\title{
Linguística textual: memória e representação
}

\author{
Leonor Lopes Fávero ${ }^{1}$
}

\begin{abstract}
Resumo: A Linguística Textual inicia-se no Brasil na década de 80 do século XX. O primeiro trabalho de que se tem notícia é de 1981, de autoria do Prof. Ignácio Antônio Neiss, intitulado Por uma gramática textual, ao qual se seguiram dois outros, em 1983: Linguística textual: o que é e como se faz, do Prof. Luiz Antônio Marcuschi e Linguística textual: introdução de Leonor Lopes Fávero e Ingedore Villaça Koch. O prof. Neiss mostra como as tentativas iniciais da linguística textual estavam, de modo geral, ligadas às gramáticas estruturais e gerativas. A obra do Prof. Marcuschi concentra-se na análise de algumas definições de texto e no estudo de aspectos teóricos em função de sua aplicabilidade. Já Leonor Lopes Fávero e Ingedore V. Koch têm como objetivo apresentar ao leitor brasileiro uma visão da linguística textual na Europa, então um recente ramo da ciência da linguagem. O trabalho insere-se na História das Idéias Linguísticas, parte da História Cultural, que procura identificar o modo como em diferentes momentos, uma realidade social é construída, pensada, dada a luz (Chartier, 1990).
\end{abstract}

Palavras-chave - linguística textual - causas do surgimento - conceituação de texto - linguística textual no Brasil

\section{PRESSUPOSTOS.}

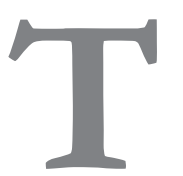

rabalho insere-se na linha de pesquisa em que venho trabalhando há anos, a História das Ideias Linguísticas. Parto do princípio que a História das Ideias Linguísticas é parte da história cultural cujo principal objeto é identificar o modo, como em diferentes lugares e momentos, uma determinada realidade social é construída, pensada, dada à luz (Chartier, 1990). Concordo com Braudel (1989:35), quando diz que "não há civilização atual que seja verdadeiramente

1 Universidade de São Paulo e Pontifícia Universidade Católica de São Paulo. E-mail: lplfavero@uol.com.br 
compreensível sem um conhecimento de itinerários já percorridos, de valores antigos, de experiências vividas"

Desse modo, vou examinar os primeiros momentos da Linguística Textual, no Brasil, passando rapidamente pela Europa, sem pretender alcançar a exaustividade, pois essa é uma das dificuldades com as quais o pesquisador sempre se depara. Quanto mais o inventário aumenta, mais esfumaçada a noção de exaustividade, ou melhor,...mais seu caráter ilusório e ideológico se afirma (Delesalle; Chevalier, 1986: 13). Ao pesquisador cabe recolher os fios que constituem esse saber, identificá-los, esticá-los para atá-los às diferentes áreas. Depois disso esses fios devem ser estendidos

(...) para trás no tempo, a fim de determinar as origens do evento e, para a frente no tempo, a fim de determinar seu impacto e influência sobre os eventos subseqüentes. Essa operação termina no ponto em que os fios desaparecem no contexto de algum outro evento ou convergem para provocar a ocorrência de algum novo evento (White,1992: 33)

$\mathrm{O}$ ato de saber possui um horizonte de retrospecção e um de projeção (Auroux, 1989) e esse saber não destrói seu passado; ao contrário, ele o organiza e o escolhe, do mesmo modo que antecipa seu futuro, pois como diz o mesmo Auroux (id.:14):

Sans mémoire et sans projet, il n’y a tout simplemente pas de savoir .

\section{A LINGUÍSTICA TEXTUAL NA EUROPA}

As fontes de que vou me servir são o livro de Wolfgang Dressler, publicado em alemão em 1972, com o título Einfubrung in die Textlinguistike em tradução italiana, Introduzione alla linguistica del texto, (1974) e o livro La linguistica textuale, organizado por Maria Elisabeth Conte e publicado em 1977. A linguística textual se desenvolveu especialmente na Alemanha : federal e democrática; houve um verdadeiro "boom". Os principais centros foram Munster, Colônia, Berlin Est, Constança e Bielefeld. O impacto foi muito grande e um levantamento bibliográfico feito em 1973 por Dressler e Schmidt documentava quase 500 títulos, alem de números especiais, monográficos, de várias revistas. 
Destacam-se os pesquisadores:

Munster: Hartmann (transferiu-se depois para Constança):

1964,1968, 1970,1971, 1975

Harweg : 1968,1969,1971,1974 - transferiu-se

depois para Bielefeld Alfred Koch

Colônia: $\quad$ H.Weinrich $(1966,1969,1971,1972)$

Elisabeth Gulich (1970, 1972, 1974)

Wolfgang Raible ((1972).

Os três transferiram-se depois para Bielefeld

Berlin Est: $\quad$ M. Bierwisch:

Heidolf

Isenberg

E. Lang

Constança: Janos Petofi - transferiu-se depois para Bielefeld

Bielefeld: $\quad$ H. Weinrich

H. Rieser

Siegfried Schmidt

Fora da Alemanha, pode-se citar van Dijk em Amsterdã e Wolfgang Dressler em Viena.

\section{A LINGUÍSTICA TEXTUAL NO BRASIL}

A linguística textual inicia-se, no Brasil, na década de 80 do século passado. O primeiro trabalho de que se tem notícia é o do Prof. Dr. Ignácio Antônio Neis da PUCRS, intitulado Por uma gramática textual, publicado na revista Letras de Hoje, revista do curso de Pós-Graduação em Linguística e Letras e do Centro de Estudos Portugueses da PUCRS, em junho de 1981, no. 44. Seguem-se, em 1983, duas obras:

Linguística de texto - o que é e como se faz de Luíz Antônio Marcuschi, publicado pela Série Debates - Revista do Mestrado em Letras da Universidade Federal de Pernambuco e 
Linguística Textual - introdução de Leonor Lopes Fávero e Ingedore Villaça Koch, publicado em São Paulo, pela Editora Cortez.

\subsection{Por uma gramática textual - Ignácio Antônio Neis}

O artigo objetiva dar uma visão de conjunto quanto ao surgimento e ao objeto da gramática textual. Divide-se em quatro partes mais uma introdução em que diz ser de grande interesse a hipótese de que

a comunicação linguística se efetua, não com frases sucessivas, mas com textos, e em qualquer texto, encontram-se elementos essenciais, ausentes ou inexplicáveis dentro das frases tomadas isoladamente

E continua:

Constatando a existência de relações específicas interfrasais e a possibilidade de se definir um texto como um todo coerente, um grande número de lingüistas modernos europeus desde a década de 60 , passaram a formular hipóteses e a estabelecer princípios de novos modelos de descrição linguística que ultrapassem o âmbito da frase; e procuraram elaborar gramáticas que dêem conta dos problemas de coerência textual e que sejam adequadas tanto para caracterizar os diversos aspectos dos diferentes tipos de textos quanto para engendrar modelos de produção de textos bem formados de acordo com determinada língua.

Quero chamar a atenção sobre dois aspectos aqui ressaltados e que marcaram essa primeira fase da linguística textual: a construção de gramáticas do texto e a importância dada por ele à coerência, vista então como propriedade do texto.

Na seqüência, faz, primeiramente, uma menção a pesquisas anteriores sobre problemas do discurso e da narrativa, e um apanhado da evolução da linguística que possibilitou chegar-se à gramática de texto ; a seguir, uma apresentação sistematizada das motivações que levaram os lingüistas a se debruçarem sobre problemas específicos do texto; e, enfim, uma exposição sobre os elementos fundamentais que constituem o objeto da gramática do texto. 
Partindo de Van Dijk (1972), afirma que, entre as teorias linguísticas, foi, sem dúvida, a gramática gerativo-transformacional a que melhor realizou uma teorização

Diz ele:

A gramática textual não só está diretamente interessada nos aspectos discutidos pela gramática gerativa, pressuposição, tema/rema, mundos possíveis, etc, como também sustenta que eles não podem ser descritos adequadamente por uma gramática frasal. De qualquer forma, é na linguística gerativa que se encontra um conjunto de procedimentos metodológicos e de descrições empíricas que servirão de base sólida para se proceder à extensão da gramática frasal para uma gramática textual.

Mostra, em seguida, as contribuições da pragmática, ressaltando os nomes de Schmidt (1978) e Van Dijk (1972) que, juntamente com os desenvolvimentos lingüísticos e metodológicos da gramática gerativa, fundamentaram hipóteses e teorias que possibilitaram a elaboração de uma gramática de texto. As principais categorias abordadas pela pragmática eram: o emissor e o receptor, as categorias de tempo e de lugar relacionadas com a enunciação, como base para a explicação dos diferentes advérbios, tempos gramaticais, termos dêiticos, aspectos contextuais os diferentes tipos de enunciações ou atos ilocucionários, com suas condições de uso, os diferentes tipos de discurso, definidos em função dos próprios objetivos e de suas normas sócio-comunicativas vigentes, etc.

Como bem mostra o autor, as tentativas iniciais da linguística textual - à qual se associam nomes de lingüistas e de teóricos da literatura - destaca Bellert, Danes, Dressler, Hartmann, Harweg, Heidolf, Schmidt e, talvez, acima de todos, Van Dijk com sua obra fundamental: Some aspects of text grammars, publicada em 1972 - ainda estão, de modo geral, ligadas às gramáticas estruturais e gerativas, mas, com a introdução da pragmática, procuram estender a gramática para a descrição e geração de seqüências gramaticais de frases

Argumenta com Van Dijk que

(...) se o falante pode produzir/interpretar um número infinito de discursos diferentes, sua competência é necessariamente textual.. Será função da gramática textual formular as regras e restrições para a concatenação 
das frases (ao nível de microestrutura) bem como para a organização do todo, em vista da coerência global (ao nível da macroestrutura).

Na última parte do seu trabalho, apresenta os elementos fundamentais de uma gramática de texto, afirmando, como já ressaltei, que "a noção fundamental da gramática textual parece ser a de coerência”.

Neiss não faz distinção entre coesão e coerência, denominando-as de coerência microestrutural e coerência macroetrutural, respectivamente.. Esta não distinção entre coesão e coerência é adotada, à época, por muitos lingüistas, como Isenberg, lingüista alemão da academia de Ciências de Berlim, um dos mais importantes centros de gramática gerativa da Europa.

Isenberg, em seu trabalho de 1971, intitulado Reflexões sobre a teoria do texto (sirvo-me da tradução italiana. in Conte, 1977), cita treze fenômenos somente explicáveis no âmbito da estrutura textual, por exemplo, a anáfora, a seleção de artigos, a pronominalização e os elementos pro-adverbiais, a sucessão dos tempos, que podem ser considerados elementos de coesão, ao lado de diversos tipos de textualização, ou seja, relações entre os enunciados assindeticamente conjugados, por exemplo, conexão causal conexão de motivos, tematização de objetos novos, estes podendo ser considerados elementos de coerência.

Como se pode ver, o trabalho de Neis foi realmente importante e pouco se faz referência a ele.

\subsection{Linguística de texto - o que é e como se faz - Luíz Antônio Marcuschi}

Em 1983, convidei o Prof. Marcuschi, por sugestão de Madre Olívia, para pronunciar uma conferência na PUCSP no IV Congresso Brasileiro de Língua Portuguesa do Instituto de Pesquisas Linguísticas, destinado principalmente a professores do ensino de primeiro e segundo graus e alunos de pós-graduação que realizávamos a cada dois anos e ele apresentou o texto do qual fez depois uma cópia simples na UFPE ( disse-me certa vez que se arrependera, pois deveria tê-lo publicado logo por uma editora conceituada). Não preciso dizer que Marcuschi, com seu carisma e competência, fez o maior sucesso. Ultrapassou em muito o tempo da conferência, as pessoas exigiram, tivemos de arrumar uma outra sala para que ele continuasse até o fim. 
Inicia o texto, afirmando que a Linguística Textual "dispõe de um dogma de fé : o texto - unidade linguísticamente superior à frase - e uma certeza: a gramática de frase não dá conta do texto” (p.16).

Diz que, procurando evitar discussões teóricas, concentrar-se-á nos tópicos:

1. análise de algumas definições de texto;

2. definição provisória da Linguística Textual e seus focos de atenção;

3. análise de alguns aspecto teóricos em função de sua aplicabildade

Apresenta, a seguir, várias conceituações de texto, de diferentes autores, como Harweg (1968), Bellert (1970), Petofi (1972), Van Dijk (1977, 1978), para, finalmente, chegar a sua, apoiado em Beaugrande e Dressler (1981): “o texto é o resultado atual das operações que controlam e regulam as unidades morfológicas, as sentenças e os sentidos durante o emprego do sistema lingüístico numa ocorrência comunicativa." (p.30).

Partindo das concepções de texto apresentadas, propões que se veja a Linguística Textual como o "estudo das operações linguísticas e cognitivas reguladoras e controladoras da produção, construção, funcionamento e recepção de textos escritos ou orais".

Baseando-se na proposta de Beaugrande e Dressler (1981) e sem preocupação classificatória - "não podemos ir além de breves incursões em terreno tão vasto” (p.31) - apresenta o esquema geral provisório das categorias textuais:

1. fatores de contextualização

2. fatores de conexão seqüencial (coesão)

3. fatores de conexão conceitual-cognitiva (coerência)

4. fatores de conexão pragmática

Leitura indispensável a todos os que se iniciam na área, visa, sobretudo "ao enfoque do aproveitamento da linguística textual em função do ensino da língua na perspectiva textual".

\subsection{Linguística textual - introdução Leonor Lopes Fávero e Ingedore Villaça Koch}

Em 1982, convidei a profa. Ingedore Villaça Kock para escrevermos sobre a Linguística Textual, resultando, nosso trabalho nesse livro publicado no 
ano seguinte (atualmente na 9 . edição) e lançado no IV Congresso Brasileiro de Língua Portuguesa na PUC/SP, o mesmo em que Marcuschi apresentou seu trabalho aqui referido. O objetivo da obra era apresentar ao leitor brasileiro uma visão da linguística textual, então um recente ramo da ciência da linguagem.

O livro compõe-se de três capítulos. O primeiro, introdutório, mostra as causas do surgimento das gramáticas textuais, apresenta sua conceituação, as diferentes abordagens teóricas e diferentes acepções dos termos texto e discurso.

O segundo capítulo, apresenta os precursores, lato e stricto sensu cujas obras estenderam-se além dos limites do enunciado (Harris, Pêcheux, Pike e outros), fazendo-se, também, referência a disciplinas que se preocuparam com uma melhor compreensão do texto e do discurso (antiga retórica, estilística formalismo russo.

O terceiro, faz uma resenha informativa de autores, quer estruturalistas, quer gerativistas que se preocuparam com as propriedades específicas dos textos (Halliday, Ducrot, Weinrich), ou com a construção de modelos de gramáticas textuais (Isenberg, Dressler, Petofi e Van Dijk). É preciso ressaltar que não se foi feita uma resenha crítica das obras, porque o objetivo foi o de dar aos leitores uma visão do que se vinha fazendo na área.

O livro constitui um instrumento importante para todos aqueles que se interessam por essa área, especialmente, alunos e professores de graduação e pós-graduação.

\section{CONSIDERAÇÕES FINAIS}

O objetivo deste trabalho foi o de apresentar os três primeiros trabalhos na área de Linguística Textual publicados no Brasil. Essas obras, resultado de cuidadosas pesquisas, visam a pôr em evidência os inúmeros problemas provenientes do estudo da conceituação de texto, suas propriedades, os momentos fundamentais da passagem da teoria da frase à teoria do texto, as causas do surgimento desta última, a descrição de alguns dos vários modelos já propostos.

\section{REFERÊNCIAS}




\title{
Textos-fonte:
}

FÁVERO, L.L. \& KOCK, I.V. Linguística Textual - Introducão. São Paulo: Cortez. 1983.

MARCUSCHI, L.A. Linguística de Texto - o que é e como se far: Recife: Série Debates 1, Universidade Federal de Pernambuco, 1983.

NEIS, I.A. "Por uma Gramática Textual". Letras de Hoje, 44, PUC/RS, 1981.

\section{Autores}

AUROUX, S. Histoire dês idées linguistiques. Paris: Pierre Mardaga éditeur, Tomo 1,1989 BEAUGRANDE, R.de \& DRESSLER,W. Einfubrung in die Textlinguistic. Tubigen: Max Niemeyer, 1981.

BRAUDEL, F. Gramática das civilizações. São Paulo : Martins Fontes, 1989.

CHARTIER, R. A bistória cultural: entre práticas e representagões. Rio de Janeiro: Bertrand Brasil, 1990.

CONTE, Maria Elisabeth. La linguística textuale. Milano: Feltrinelli, 1977.

DELESALLE, S. \& CHEVALIER, J.C. La linguistique, la grammaire et l'école (1750-1914) Paris: Armand Colin, 1986.

DIJK, T.A. van. Some Aspects of Text Grammar . Paris, The Hague, Mouton, 1972

DRESSLER, W. Einfubrung in die Textlinguistic. Tubigen: Neimeyer, 1972. Trad. ital. Introduzione alla Linguística del Texto. Roma: Officina, 1974.

Wilhem Fink, 1973.

\& SCHMIDT, S.J. Textlinguistik: Kommentierte Bibliographie. Munchen,:

WHITE, H. Meta-História: a imaginaşão histórica do século XIX. São Paulo: EDUSP, 1992

\section{Text linguistics: memory and representation}

\begin{abstract}
Text Linguistics originates in Brazil in the 80s of the twentieth century. The first work that we know of is from 1981, authored by Prof. Ignacio Antonio Neiss, entitled Por uma gramática textua, which was followed by two other in 1983: Linguística textual: o que é e como se faz, by Prof. Luiz Antônio Marcuschi and Linguística textual: introdução by Leonor Lopes Favero and Ingedore Villaça Koch. Professor Neiss shows how initial attempts to textual linguistics, were generally related to structural and generative grammars. The work of Prof. Marcuschi focuses on the analysis of some text definitions and on the study of theoretical aspects in relation to their applicability. Leonor Lopes Favero and Ingedore V. Koch aim to provide the Brazilian reader with an overview of text linguistics in Europe, a recent branch of language science then. This work is part of the History of Linguistic Ideas, part of the Cultural History, which seeks to identify how at different times, a social reality is constructed, designed, and enlightened (Chartier, 1990).
\end{abstract}

Keywords - text linguistics - emergence causes - text conceptualization - text linguistics in Brazil 